\title{
EDUCATION AS A MORAL ENTERPRISE FOR ADOLESCENTS
}

\author{
Prakash Chandra Jena \\ School of Education, Lovely Professional University, Punjab, India \\ E-mail address: drpcjena@gmail.com
}

\section{Keywords: Moral Values, Adolescents, Curricular and Co-curricular Activities}

\begin{abstract}
Identifying various problems of school going adolescents is a major challenge nowa- days. This paper focuses various educational problems of adolescents and how these problems cause for their moral degradation. For inculcating moral value among them curricular and cocurricular activities play a vital role. It is an attempt to suggest some educational activities taking into account the interest of adolescents that create a plat for all-round development of their personality and peace survival in the society.
\end{abstract}

\section{INTRODUCTION}

Adolescents form a major portion of countries population and development of the country depends upon healthy youth. Adolescence is critical growth spurt in one's life. This is an age when adolescence is critical growth spurt in ones life. This is an age when adolescents are unaware and very men to know about their sexuality. Consequently get involved in different sexual activates. They may face many problems related to sexual issues and rights as they lack knowledge about physical, psychological changes accompanying their growth and development.

The adolescents rising interest and curiosity about sex are a motivation factor to acquire information about it. Confronting face to face with the urge to explore sexuality are the present social norms and taboos. This leads to many misconceptions and mal-information resulting in adolescence boys and girls trying to experiment sex and especially girls become more vulnerable to teenage pregnancy or have to bear the brunt of sexually transmitted disease. This is because they hesitate and lack communication with their parents, teachers or elders to have open frank discussions regarding sexual issues. In Indian families parents are not open with their youngsters to talk about sexual issues and rights, which ultimately affect the curiosity, knowledge as well as perception regarding these issues.

The world is passing through great crises in almost all spheres of life. Social living in today's changing trends, which is marked by tremendous scientific and technological advancement, has resulting in an explosion of aspiration for achieving material goals. Globalization has brought an upheaval in the economic scenario worldwide. These, in turn, have brought about a corresponding decline in human's moral, spiritual and ethical values creating many problems, tension, conflict, competition, social distance, alienation and rivalries among human beings. These are nothing but manifestations of violence of one form or the other. In short, materialization is the keyword among new attitudes to life and living. The changes in lifestyles, family patterns and environment as a result of industrialization, urbanization and modernization have contributed to the increase in delinquency rates so becoming a cause of concern. Life is undergoing a significant transition and change and among the most affected are the adolescents (Swain, 2011 and Barma, 2011). Today, India is also in the grip of octopuses of problems to its neck. The whole country is experiencing a massive erosion of values (Chenera,2009). Balamohandas (2008) adds that political and economic corruption, scandals and scams, anti social and anti-national activities are on the rise all over the country. Das (2009) is of the opinion that modern civilization is becoming increasingly more materialistic, socially- insensitive and disoriented. Now-a-days newspapers, magazines and other channels of media are flooded with reports of crimes, murder, agitation, eve-teasing, disputes between parents and children, teachers and students, husbands and wives and in-laws. Incidence of 
violence, destruction, killing each other in the name of insurgency, strikes and lock-out are becoming more and more common. These occurrences indicate deterioration in environment, ethical standards, moral and social values and people's aspiration for acquisition of more power, that is, money and more money by fair means or foul.

\section{MORAL VALUES:}

'Value' comes from the Latin word 'valere', which means to be of worth, to be strong. The dictionary gives the following meaning: relative worth utility or importance, degree of excellence, something intrinsically valuable. Values are those standards or codes of conduct, which are conditioned by one's cultural tenants, guided by conscience, according to which one is supposed to conduct himself and shape his life pattern by integrating his beliefs, ideas and attitudes with a view to realize the cherished ideals and aims or life. In the words of Dewey, "the value means primarily to price, to esteem, to appraise and to estimate". It means the act of achieving something, holding it and also the act of passing judgment upon the nature and amounts of values as compared with something else. Dewey (1989) indicates that his concept of values include a) The idea of praising, cherishing and holding idea. b) The idea of reflection and making connections between the factors of the situation in one's existence to the end that intelligence is employed and that improved judgement is concluded. c) The idea that action is supported of an approved value will be taken. Abdul Kalam (2007) "Mission of education", is the foundation to ensure the creation of enlightened citizens, who will make a prosperous, happy and strong Nation. Lalitha, P. R. (2001). Moral values refer to objects that human beings consider desirable and worthy of pursuit in their thoughts, feelings and actions. These may be heart like truthfulness, happiness, peace, justice. In either case, they function as ideals and standards that govern human actions. Moral values are the essential building blocks of our character and nature and the sum total of our character.

Lalitha, P. R. (2001) in her article titled "Value Inculcation in the context of Science" says that a need is felt to humanize science education by cultivating values through a new order based on scientific and technological training. We need to produce students of science with responsibility. If Science is to be relevant to life today and life in future, Science teachers have no alternative but to consider the relationship between science and values. Values are the highest among all natural values. Goodness, purity, truthfulness, humility of man rank higher than genius, brilliancy, exuberant vitality, than the beauty of nature or of art, than the stability and power of a state. What is realized and what shines forth in an act of real forgiveness, in a noble and generous renunciation; in a burning and selfless love, is more significant and more noble, more important and more eternal than all cultural values. Positive moral values are the focus of the world, negative moral values, the greatest evil, worse than suffering, sickness, death, or the disintegration of a flourishing culture.

\section{EDUCATION AS A MORAL ENTERPRISE}

We trust that it is uncontroversial to say that schooling is unavoidably a moral enterprise. Indeed, schools teach morality in a number of ways, both implicit and explicit. Schools have a moral ethos embodied in rules, rewards and punishments, dress codes, honor codes, student government, relationships, styles of teaching, extracurricular emphases, art, and in the kinds of respect accorded students and teachers. Schools convey to children what is expected of them, what is normal, what is right and wrong. It is often claimed that values are caught rather than taught; through their ethos, schools socialize children into patterns of moral behavior.

Textbooks and courses often address moral questions and take moral positions. Literature inevitably explores moral issues, and writers take positions on those issues as do publishers who decide which literature goes in the anthologies. In teaching history we initiate students into particular cultural traditions and identities. Although economics courses and texts typically avoid overt moral language and claim to be "value free," their accounts of human nature, decision making, and the economic world have moral implications, as we have seen. 
The overall shape of the curriculum is morally loaded by virtue of what it requires, what it makes available as electives, and what it ignores. For example, for more than a century (but especially since A Nation at Risk and the reform reports of the 1980s), there has been a powerful movement to make schooling and the curriculum serve economic purposes. Religion and art, by contrast, have been largely ignored (and are not even elective possibilities in many schools). As a result, schooling encourages a rather more materialistic and less spiritual culture a matter of some moral significance.

Educators have devised a variety of approaches to values and morality embodied in selfesteem, community service, civic education, sex education, drug education, Holocaust education, multicultural education, values clarification, and character education programs - to name but a few. We might consider two of the most influential of these approaches briefly. For the past several decades values clarification programs have been widely used in public schools. In this approach, teachers help students "clarify" their values by having them reflect on moral dilemmas and think through the consequences of the options open to them, choosing that action that maximizes their deepest values. It is unjustifiable for a teacher to "impose" his or her values on students; this would be an act of oppression that denies the individuality and autonomy of students. Values are ultimately personal; indeed, the implicit message is that there are no right or wrong values. Needless to say, this is a deeply controversial approach — and is now widely rejected.

The character education movement has been a response, in part, to the perceived relativism of values clarification. According to the "Character Education Manifesto," "all schools have the obligation to foster in their students personal and civic virtues such as integrity, courage, responsibility, diligence, service, and respect for the dignity of all persons" (Boston University, 1996). The goal is the development of character or virtue, not correct views on "ideologically charged issues." Schools must become "communities of virtue" in which "responsibility, hard work, honesty, and kindness are modeled, taught, expected, celebrated, and continually practiced." An important resource is the "reservoir of moral wisdom" that can be found in "great stories, works of art, literature, history, and biography."Education is a moral enterprise in which "we need to reengage the hearts, minds, and hands of our children in forming their own characters, helping them 'to know the good, love the good, and do the good' (Boston University, 1996).

Finally, we note what is conspicuous by its absence: although all universities offer courses in ethics, usually in departments of philosophy or religious studies, very few public schools have such courses. Unlike either values clarification or character education programs, the major purpose of ethics courses is usually to provide students with intellectual resources drawn from a variety of traditions and schools of thought that might orient them in the world and help them think through difficult moral problems. As important as we all agree morality to be, it is striking that schools do not consider ethics courses an option worth offering.

\section{DEVELOPMENT OF VALUES THROUGH EDUCATION}

To make the value aspect of our education programmes more prominent, the following ideas may be incorporated in the educational programmes.

- Developing self-respect, awareness of self-growth, one's uniqueness, self-confidence.

- Promoting selflessness, cooperative spirit, spirit of sharing.

- Cultivating respect for property, one's own and that of other.

- Understanding the contribution of home towards the physical, emotional, cultural and spiritual development of young people.

- Imparting clear direction on cleanliness, punctuality, use of refined language, courtesy, proper manner, respect for elders.

- Knowing of surroundings-visiting slums, villages, hospitals, orphanages, old people's homes.

- Becoming aware of the need of the others.

- Promoting civic scene, awareness of oneself as a member of a community, civic duties. 
- Awareness of one's strength and weakness, and also those of others.

- Love of friends, classmates, and the not so fortunate.

- Seeking to realize one's potentialities and talents, disciplined learning in academics, sports, cultivating the scientific temper.

- Independent thinking, not blindly following others.

- Exposure to great personalities.

- Knowledge of the constitution, rights, and duties.

- Knowing the provision to promote human dignity and justice, patriotism, national integrity, international understanding.

- Protection of environment.

- Dissemination of cultural heritage.

- Modifying human behavior through values.

- Knowing one's village/city, state, country.

- Promotion of equality and justice for all the citizens.

- Prayer of various religions.

- Awareness of good point in other religions.

- Appreciating the useful views of others and their cultural traditions.

- Propagation of value philosophy.

\section{CONCLUSION}

Due to many problems faced, school going adolescents but their problems are specific to themselves. Most of the problems faced by them are perceptional. By timely and effective guidance many of their problems could be solved. Some of them may need medical / psychiatric attention. In India, the parents influence their behaviour, thoughts and are in position to solve many problems if they have positive approach. Despite all efforts being made by parents, teachers, large numbers of adolescents face one or many problems. When the problem is aggravated, the parents may take them to doctors. But most of them face minor problems modifying their behavioural patterns, personality as a whole. The implications of problems can be moral or social.

In order to inculcate values among students, teacher should have value charged personality.

- The curriculum be redesigned in a way to inculcate values.

- Education alone cannot change the value system of the society. There are always conflicts between the values taught at the school and values that a child receives at the home.

- The mass media and press have a great influence on the children and youth to inculcate values.

\section{References}

[1] Kour S. \& Dillon S.K. (2011). Value Education. Kasturi Lal \& Sons. 5-6.

[2] Lalitha, P.R. (2001). Value inculcation in the context of science. Journal of Value Education.1(1).

[3] Leming, J. (2006). Curricular Effectiveness in Moral/Values Education: A Review of Research. Journal of Moral E ducation, 10(3), 17.

[4] Mondal B. C. \& Jayanta M. (2009). Value awareness among secondary school students of West Bengal. Sikshachinan, 3, 72-76.

[5] Santhosh Arora (2003). Modernization and Human values. The Educational Review. 46(8), 155. 
[6] Sharma, R.A. (2011). Human Values and Education. Vinay Rakheja Publication. Meerut. 99102.

[7] Singh J. \& Sandhu N. (2011) Impact of television commercials on the social and moral behavior of indian viewers - empirical evidence.

[8] Thomas M. (2011). Parent and peer influences: their role in predicting adolescent moral values and delinquent behavior. New Ideas in Psychology 27, 96-106.

[9] Vijayalakshmi G. (2006). Prioritization of secondary school childrens' values by their parents and teachers, Edutracks, 5(7), 34.

[10] Yashodha \& Talwar M.S. (2013). Value Education. APH Publishing Corporation. 180-205. 